\title{
Erratum to: A holistic approach for evaluating liquid explosive detection systems
}

\author{
Olive Emil Wetter • Mirjam Fuhrer
}

Published online: 15 September 2013

(C) Springer Science+Business Media New York 2013

\section{Erratum to: J Transp Secur \\ DOI 10.1007/s12198-013-0122-2}

The original version of this article unfortunately contained some incorrect information. Please refer to the correct information below.

Results, 3rd paragraph, line 4, should say: “... 12 cases out of 380 scanned LAGs, ...” Fig. 2 should look as follows:
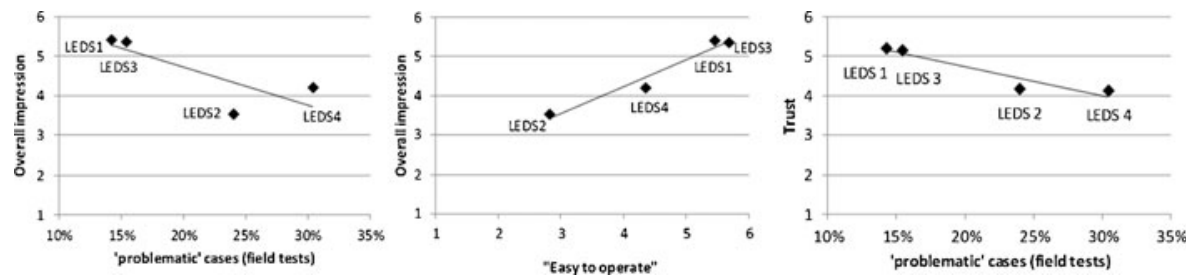

Fig. 2 Relation of SOs' overall impression and number of 'problematic' cases (a, left); overall impression and operability (b, center); trust and number of 'problematic' cases (c, right)

Consequently, the wording of the 4th paragraph of the discussion has to be slightly adapted:

lines 4-8: "We found a relation between the subjective overall impression of the devices and their rate of 'problematic cases' (i.e., LAGs that either produced a false alarm or could not be scanned). Another relation was found between the overall impression and the judgment of "how easy to operate" the device was."

The online version of the original article can be found at http://dx.doi.org/10.1007/s12198-013-0122-2.

O. E. Wetter · M. Fuhrer

Airport Division, Research \& Development, Kantonspolizei Zürich (Zurich State Police), Zurich, Switzerland

O. E. Wetter $(\bowtie)$

Airport Division, Research \& Development, Kantonspolizei Zürich, CH-8058 Zurich-Airport,

Switzerland

e-mail: weto@kapo.zh.ch 